\title{
EDUCAÇÃO, BARBÁRIE E SEMIFORMAÇÃO: APORTES DA TEORIA CRÍTICA E DO PENSAMENTO ADORNIANO PARA ANALISE DA PRÁTICA EDUCATIVA
}

\section{Thiago Luiz Santos Oliveira}

\section{RESUMO}

Neste artigo procurar-se-á abordar a relevância dos conceitos de educação barbárie e semiformação, a partir do pensamento crítico de Theodor Adorno para o entendimento da prática educativa. Dentro dessa perspectiva buscar-se-á evidenciar a importância da educação para a superação dos processos de dominação e para a formação de sujeitos realmente plenos, capazes da reflexão autônoma. É importante frisar no entanto que Adorno e os fundadores da matriz da Teoria Critica, posteriormente conhecida como Escola de Frankfurt não eram especificamente teóricos da educação. Mesmo assim é possível e pertinente a utilização do arcabouço teórico adorniano nas reflexões acerca da pratica educativa. Ora, sendo a educação enquanto campo de pesquisa social pautada pela pluralidade de análises e pela interdisciplinaridade faz-se importante o entendimento epistemológico dos preceitos principais que norteiam a Teoria Crítica, que podem de fato ser utilizados para a análise sociológica da pratica pedagógica.

Palavras Chaves: Teoria Crítica, Educação, Indústria Cultural, Barbárie, Formação.

\begin{abstract}
In this article we will try to approach the relevance of barbarism education concepts and erudition, from critical thinking Theodor Adorno to the understanding of educational practice. Within this perspective will be sought to evidence the importance of education to overcome the domination of processes and the formation of subjects really full, capable of independent thought. It is important to note however that Adorno and the founding mother of Critical Theory, later known as the Frankfurt School were not specifically educational theorists. Yet the use of Adorno's theoretical framework in the reflections of the educational practice is possible and relevant. Now, with education as a social search field guided by the plurality of analysis and the interdisciplinarity is an important epistemological understanding of
\end{abstract}


the key principles that guide the Critical Theory, which can in fact be used for sociological analysis of pedagogical practice.

Keywords: Critical Theory, Education, Cultural Industry, Barbarism, Formation.

\section{Teoria Crítica e educação}

A relevância do arcabouço sociológico da Teoria Crítica na análise das praticas escolares e na superação da massificação do indivíduo é patente. Portanto neste trabalho pretende-se a interlocução constante entre a Teoria Crítica, o pensamento adorniano que a ela em termos epistemológicos se filia, e o próprio sentido da práxis pedagógica. A prática educativa é primaz na superação da barbárie, mediante analise das representações e significações da educação na sociedade capitalista contemporânea, sobretudo no que tange à massificação e mercantilização dos bens culturais e educacionais.

A prática educacional é sempre uma forma de práxis social, carregada de tensão, e com uma lógica pedagógica própria, o que a difere de outras práticas sociais. O entendimento da realidade da escola só é possível por meio de processos hermenêuticos que objetivem o desvelamento da realidade social. Trata-se de uma questão dialética, onde estão concatenadas a reflexão teórica e a realidade social observada. (PFLUGMACHER, 2012).

Segundo Adorno:

A dialética não permite que nenhuma exigência de pureza lógica a impeça de passar de um gênero a outro, de fazer com que a coisa fechada sobre si própria se ilumine através do olhar voltado para a sociedade, de apresentar à sociedade a conta que a coisa não é capaz de pagar. (ADORNO 1998, p.24).

Mediante a temática proposta no título deste capítulo procurar-se-á elucidar aspectos referentes á importância e relevância da educação na superação da barbárie e do processo de Halbbildung ${ }^{1}$. Mais do que analisar a pertinência do termo Indústria Cultural, busca-se demonstrar a importância de uma educação emancipadora, que possibilite a ruptura com o processo de massificação e contribua para a Bildung ${ }^{2}$ na autonomia do sujeito.

Em termos epistemológicos a Teoria Crítica contesta a premissa de que a sociologia é a ciência da verificação e não da intervenção. Para tal tradição de
${ }^{1}$ Semiformação, que mediante o pensamento adorniano significa os impeditivos à formação plena do sujeito. A semiformação não se refere em seu conceito epistemológico, a ausência de formação intelectual e técnica, mas sim a primazia do conhecimento tecnificado sobre um conhecimento humanizante, o que de fato é impeditivo a uma formação plena e esclarecida.

${ }^{2}$ Formação do sujeito pleno e esclarecido, capaz de pensar por si mesmo, em termos críticos e reflexivos. A formação é pressuposto básico para a humanização que tolhe e impede a barbárie. 
pesquisa a sociologia chamada de positivista se torna conformista quando se coloca como uma ciência apenas descritiva, e não atuante. Faz-se necessária então uma reflexão, uma crítica aos princípios e a atitude metodológica da própria sociologia. Dentro dessa perspectiva, a crítica social se faz patente, numa relação dialética com a investigação empírica e com a observação. A crítica social é imanente à própria pesquisa sociológica, não sendo possível a dissociação.

Mas, acima de tudo, a sociologia que quer reconhecer somente o "positivo" corre o perigo de perder toda a consciência crítica. Tudo que é diferente desse "positivo" e obriga a formular interrogações sobre a legitimidade de uma determinada entidade social, em vez de se limitar a comprova-la e classifica-la, como dado verificável, torna-se alvo de suspeitas. (ADORNO; HORKHEIMER, 1973, p.21).

Dessa forma percebe-se na construção intelectual da Teoria Crítica que a sociologia enquanto ciência não pode se ater à rigidez metodológica, ou a preceitos técnicos. A sociologia, principalmente no que concerne à educação deve buscar ser uma ciência ética, que resgate uma perspectiva humanista, onde a investigação procure mais do que a observação e o discernimento purista do fenômeno social, mas que sobre tudo também seja uma ciência da contribuição, uma ciência da possibilidade de transformação da sociedade e do individuo.

Para Cohn (2009) a primeira observação concernente a critica adorniana a sociologia enquanto ciência reside na importância que se atribuía à observação em detrimento da teoria. Adorno era um crítico contundente da "[...] primazia concedida aos dados da observação sem mais, reservando posição subalterna à teoria reduzida a mero subproduto da pesquisa." (COHN, 2009, p. 20). Isto não significa que enquanto cientista social Adorno não considerasse a importância do método, da descrição, da coleta e da observação dos dados, mas sim acreditava de forma veemente que a construção teórica e a reflexão não poderiam de forma alguma serem desconsideradas do processo de pesquisa sociológica. Era necessário então estabelecer uma relação dialética entre o empirismo e a teoria.

Dentro dessa perspectiva percebe-se que Teoria Crítica deitou seu olhar crítico sobre a importância do conceito na pesquisa social. A partir deste posicionamento o conceito se torna mais do que mera nominação a um fenômeno, ou objeto social estudado. O conceito é parte intrínseca do objeto, é algo que é evidenciado além da aparência. A dinâmica da pesquisa sociológica calcada no 
positivismo não captava essa dimensão imanente dos conceitos acerca dos objetos e fenômenos sociais. A sociologia deveria então buscar a "essência" dos fenômenos e dos processos sociais. Aquilo que é aparente é reflexo daquilo que é intrínseco, daquilo que faz parte da constituição do objeto. Por isso para Adorno além de simplesmente observar, é necessário que a sociologia teorize, reflita sobre os fenômenos sociais, e sobre o componente humano. Mais do que refletir propõe-se uma sociologia da investigação empírica, onde teoria e prática se concatenam para melhor contribuir com a ação efetiva do homem na sociedade.

Sabemos que um dos pontos centrais da crítica de Adorno à sociedade contemporânea é a de que nem esta nem os indivíduos que a compõem tem como se alçar à condição de sujeitos, obstados que estão pela conformação da totalidade histórica em curso. (COHN, 2009, p.30).

Faz-se necessário então que a sociologia busque as sutilezas, aquilo que aparentemente é secundário, que esmiúce os aspectos mais finos e subliminares da sociedade, aquilo que corresponde a "essência", aquilo que é pouco perceptível. Numa concepção adorniana é importante então que o empírico negocie e dialogue com o teórico, é necessário que a ciência "pense além"3.

Talvez uma das principais implicações filosóficas educacionais do pensamento de Adorno refira-se a defesa intransigente de um modo de pensar, que não se entrega diante das facilidades de um raciocínio condicionado a permanecer na superfície do dado imediato. O frankfurtiano defende, pelo contrário a manutenção de um pensamento que ensina a ler as entranhas de cada objeto analisado. (ZUIN; PUCCI; OLIVEIRA, 2001, 109).

Adorno procurava valorizar a reflexão e a crítica no estudo sociológico. Para ele a sociedade interage de forma dialética com o indivíduo, são polos comunicativos constantes, e essa relação deve sempre ser considerada. Dessa forma, mais do que pensar a sociedade, a sociologia a partir de um prisma adorniano deve pensar o homem, nos seus conflitos e problemas, inserido nesta mesma sociedade. A sociologia então deve perpassar as amarras do positivismo e evocar enquanto questão principal o homem, contribuindo empiricamente para que este mesmo homem supere suas questões, seus problemas, buscando na investigação das questões sociais mostrar que é possível a emancipação do individuo.

${ }^{3} \mathrm{Na}$ tradiç̃o do pensamento adorniano significa pensar o próprio pensamento, ou seja, a reflexão racional que leva ao esclarecimento. 
A partir de uma leitura crítico-reflexiva da Teoria Crítica, sobretudo a partir da construção intelectual de Adorno uma das principais responsabilidades do processo educacional, é romper com a barbárie. E o que seria barbárie? A barbárie é a violência não só no âmbito físico, mas também a ausência das mínimas condições para que o individuo se realize. Bem, dessa forma a educação deve objetivar a liberdade e a promoção da capacidade de reflexão crítica e emancipação dos indivíduos. A educação deveria então se configurar como ferramenta para a humanização e a escola um dos principais lócus deste processo. "Dessa feita, outra contribuição filosófica-educacional e a de que Adorno estimula a importância do pensamento que reflete sobre si mesmo.” (ZUIN; PUCCI; OLIVEIRA, 2001, p.112). Assim a educação seria condição básica para a luta contra a massificação e a alienação, promovendo a formação de indivíduos cultos e responsáveis, prontos para intervir de forma ética numa sociedade de vertente democrática.

O problema que se impõe nesta medida é saber se por meio da educação pode-se transformar algo de decisivo em relação à barbárie. Entendo por barbárie algo muito simples, ou seja, que estando na civilização do mais alto desenvolvimento tecnológico, as pessoas se encontram atrasadas de um modo particularmente disforme em relação a sua própria civilização. (ADORNO, 2011b, 155).

A barbárie se dá na não correspondência entre o estado do desenvolvimento tecnológico e o desenvolvimento humano. A primazia da técnica constrói um invólucro aparente de progresso, mas que de fato não considera o entendimento do outro como algo possibilitado pela razão. A razão se torna meramente instrumental, e perde sua capacidade esclarecedora e cidadã. A subjetividade não encontra espaço para se realizar enquanto experiência cotidiana autônoma. A autonomia humanista é suprimida, e o domínio técnico é elevado ao "Olimpo" social. No lugar da emancipação, percebe-se a pujança da reificação ${ }^{4}$, da materialização da própria consciência cooptada que perde seu caráter abstrato se tornando dogmática e totalizante. Padrões são repetidos, na moda, na produção cultural, nas formas de pensar e de agir. Perde-se o componente autônomo da razão que permite e tolera a diferença.

${ }^{4}$ Conceito marxista denotativo de um tipo de alienação, onde as relações sociais e conceitos abstratos são tratados como objetos materiais. 


\section{Indústria Cultural como processo de dominação}

Para Adorno e Horkheimer (2006) na sociedade contemporânea, de capitalismo avançado, tudo ganha um ar de semelhança. Essa similitude desenvolvida pela reificação das consciências, pela fetichização ${ }^{5}$ da cultura e pela imposição verticalizada, tanto de bens matérias como de bens culturais é a própria Indústria Cultural. Padrões são repetidos e reproduzidos, e a racionalidade torna-se um elemento de dominação, à medida que não estimula a reflexão. Assim cada indivíduo "[...] deve se comportar, como que espontaneamente, em conformidade com seu nivel, previamente caracterizado por certos sinais, e escolher os produtos de massa fabricados para o seu tipo.” (ADORNO HORKHEIMER, 2006, p.102). Dentro dessa perspectiva, o autor tece considerações acerca das características similares das edificações nas zonas urbanas. Tudo é igual, tudo é padronizado, das edificações á estética das ruas e avenidas. A Indústria Cultural cria uma falsa impressão totalizante, daquilo que na verdade é particular, o que traduz o domínio das massas por um grupo restrito. Os padrões estabelecidos nessas relações de dominação retiram do individuo a capacidade de agir de forma crítica e reflexiva. $\mathrm{O}$ cientista social disserta ainda acerca da importância dos meios de comunicação neste processo. Os meios de comunicação difundem padrões, e estéticas a serem avidamente consumidos pelas massas de forma objetiva, uniformizada, sendo na verdade um instrumento de controle. A Indústria Cultural padroniza até os aspectos referentes ao lazer e à diversão. Mesmo nos momentos de lazer o indivíduo segue modelos e roteiros esquemáticos, como se estivesse numa linha de produção.

O mundo inteiro é forçado a passar pelo filtro da indústria cultural. A velha experiência do espectador de cinema, que percebe a rua como um prolongamento do filme que acabou de ver, porque esse pretende ele próprio reproduzir rigorosamente o mundo da percepção quotidiana, tornou-se a norma da produção. (ADORNO, HORKHEIMER 2006, p. 104).

A Indústria Cultural torna o estilo uma caricatura. Não existe autenticidade, não existe singularidade, o estilo apenas traduz uma forma de dominação. O estilo para os grandes artistas, por exemplo, era uma forma de refletir, de pensar a realidade, era uma maneira comprometida de expressão, de negação. Para a Indústria Cultural o estilo se torna algo corrompido, se torna instrumento de dominação, de imposição.

${ }^{5}$ Mediante a tradição do pensamento marxista, quando a própria interação psicológica do

indivíduo em relação ao objeto ganha uma caráter mercantilizado. 
O próprio capitalismo cria um sistema de dominação que neutraliza a capacidade de critica e de reflexão do indivíduo. Esses artifícios de dominação são intrínsecos ao sistema, portanto de difícil rejeição. Para Adorno a crítica é dotada de um caráter histórico, de inserção e capacitação do homem para pensar o mundo a partir das suas demandas enquanto sujeito histórico. A sociedade contemporânea, a sociedade do capitalismo administrado se caracteriza pela padronização cultural, onde a venda de bens culturais se torna um mecanismo de controle social. A Indústria Cultural constrói um sentido de estética restrito, padronizado, ao mesmo tempo "massificante". A Indústria Cultural ao estabelecer padrões estéticos e de consumo de uma maneira verticalizada promove relações de dominação, servindo ao interesse de grupos sociais específicos, controlando a consciência dos indivíduos, que são expropriados da sua capacidade de reflexão, e apenas assimilam aquilo que é imposto. "A indústria cultural é a integração deliberada, a partir do alto, de seus consumidores. Ela força a união dos domínios, separados há milênios, da arte superior e da arte inferior. Com o prejuízo de ambos." (ADORNO, 1972, p.286). Na sociedade contemporânea de capitalismo administrado, aquilo que se torna validado verticalmente pela Indústria Cultural, torna-se uma verdade apropriada de forma acrítica, o que de fato gera uma falsa consciência, de que aquilo que na realidade é uma construção particular é uma verdade total. Processa-se então o controle das consciências, numa tendência totalizante e homogeneizante.

Para Adorno e Horkheimer (2006) a utilização do termo Indústria Cultural se faz mais apropriado do que "cultura de massa". Os dois cientistas sociais postularam que o sentido de "cultura de massas" poderia ser equivocadamente utilizado, sugerindo uma cultura eminentemente popular que emanaria do povo, uma arte popular. Ora, sabe-se que para Adorno a arte se distinguia de forma patente da Indústria Cultural e dos seus produtos. A Indústria Cultural age de forma verticalizada, de cima para baixo, sendo um instrumento de controle e condicionamento das massas.

Cultura de massas parece indicar uma cultura solicitada pelas massas, como se fossem sujeito pressuposto acriticamente, fora do alcance da totalização. Já o termo indústria cultural ressalta o mecanismo pelo qual a sociedade como um todo seria construída sob a égide do capital reforçando o vigente. (MAAR, 2003, p. 2). 
Na concepção da Teoria Crítica a Indústria Cultural exclui a perspectiva crítica do indivíduo e os bens culturais se tornam mercadorias. O homem perde sua capacidade de individuação ${ }^{6}$, de ser vetor de transformações sociais, políticas e culturais. O indivíduo não é sujeito de suas escolhas, mas sim objeto das ações da Indústria Cultural. Normalmente aquilo que a Indústria Cultural apresenta como novo, é apenas um verniz sobre aquilo que já foi apresentado. A Indústria Cultural ao operar sobre as massas cria padrões universalizantes e totalizantes de ação, de pensamento, desconsiderando aspectos que proporcionem a reflexão e a analise crítica.

$\mathrm{Na}$ "sociedade de massas" pautada pelo domínio da Indústria Cultural, a reprodução da vida principalmente no que tange as suas condições materiais e imateriais são dotadas de um caráter homogeneizante. Dessa maneira na formação social capitalista percebe-se certo determinismo no que se refere às opções do sujeito. O que de fato parece escolha é algo determinado previamente e concebido pela Indústria Cultural. As "massas" são semiformadas à medida que não constroem reflexões acerca de suas escolhas, mas sim reproduzem como cópia as afirmações e modelos já vigentes. $\mathrm{Na}$ "sociedade massificada" o mundo do indivíduo é pautado por uma sistematização que substitui a experiência, e por consequência a reflexão. $\mathrm{O}$ sujeito semiformado se torna um prolongamento da produção da Indústria Cultural. Aquilo que é colocado por um grupo, é validado como verdade universal, o que gera uma falsa consciência, uma cópia a ser reproduzida como realidade imposta ao sujeito. Dessa forma, os indivíduos aderem a essa lógica imposta pela Indústria Cultural. Além de aderir, se sujeitam à lógica do capital.

A partir do momento em que as mercadorias, com o fim do livre intercâmbio perderam todas as suas qualidades econômicas salvo seu caráter de fetiche, este se espalhou como uma paralisia sobre a vida da sociedade em todos os seus aspectos. As inúmeras agências da produção em massa e da cultura por ela criada servem para inculcar no indivíduo os comportamentos normalizados como os únicos naturais, descentes e racionais. (ADORNO; HORKHEIMER, 1973, p.21).

A Indústria Cultural debilita a individualidade, ao ponto que produz a massificação, pautando as relações pela lógica do mercado, tanto em termos objetivos como subjetivos. O pensamento crítico é dificultado uma vez que a repetição de padrões ditados acontece de forma ressonante, sendo de difícil rejeição

${ }^{6}$ Capacidade do individuo, mediante a Teoria Crítica de agir por sim mesmo, de forma emancipada e autônoma. 
pelos indivíduos. Esse processo de fetichização, onde os bens culturais, e o próprio afeto se transformam em mercadorias, tolhe e cerceia o indivíduo em sua humanidade, muitas vezes aproximando-o da barbárie. A ideologia se confunde com a própria cultura. Em uma sociedade massificada, percebe-se que a própria escola muitas vezes é veiculadora dessa ideologia totalizante, à medida que não a critica, simplesmente adere às veleidades da massificação. "Em vez disto a argumentação deveria voltar para os sujeitos que são os interlocutores.” (ADORNO, 2011d, p. 48). O homem enquanto sujeito social, que de fato opera sobre a dinâmica política, social e econômica do mundo deveria assumir seu papel de protagonista da práxis ativa. A Indústria Cultural no seu processo de massificação inverte esta lógica, corrompendo o sujeito em sua ação autônoma, uma vez que a autonomia em um mundo massificado se torna uma falácia retórica.

\subsection{Processo de dominação, semiformação e o desafio da educação}

O entendimento da Indústria Cultural relaciona-se com o a matriz de uma sociedade que estabelece cópia dela mesma, reproduzindo de forma acrítica essa mesma sociedade, que já se traduz como cópia. Dentro dessa perspectiva a cultura enquanto ideologia permeia toda sociedade. O processo dialético é congelado o que gera uma sociedade semiformada. A semiformação é fruto de um complexo enlace das relações sociais, econômicas e políticas dominantes. É a sujeição a aquilo que se adere, àquilo que é socialmente estebalecido de forma não reflexiva e determinante. Para romper com esta lógica estruturante faz-se necessário perceber as condições objetivas determinantes em meio aquilo que é subjetivo, assim percebendo o que é a dialética da produção, intervindo na realidade histórica e social.

Primordial na questão da semiformação é não perder de vista a constelação em que dá seu foco Para Adorno não basta examinar formação, semiformação ou cultura, tais como se verificam na sociedade vigente. É preciso investiga-las tendo como referencia o contexto de produção da sociedade, como formação social autogerada pelos homens e aprendida em sua dialética histórica. Cultura e formação precisam ser examinadas fora do âmbito estritamente cultural e pedagógico definidos na sociedade, para serem investigadas no plano da própria produção social da sociedade em sua forma determinada. A via régia de acesso ao essencial é o processo de sua reprodução vigente em seu aparecer real e presente. (MAAR, 2003, p.10). 
A superação dessa realidade só seria possível pela negação, pela crítica. A reflexão possibilitaria a emancipação do sujeito, a superação das determinações objetivas.

O mundo dos homens é organizado de determinada maneira e é preciso decifrar as condições e os condicionantes que causam seu modo determinado de ser. A emancipação como conscientização é a reflexão racional pela qual o que parece natural, essencial na sociedade cultural, decifra-se como ordem socialmente determinada em dadas condições da produção real efetiva da sociedade. (MAAR, 2003, p.14).

O processo de massificação é algo tão presente na sociedade tecnificada, que a vida passa a ser organizada pela lógica da divisão técnica do trabalho. A Indústria Cultural necessita de consumidores acríticos, que não questionem essa lógica de mercantilização das relações sociais. Dentro desse contexto totalizante, apenas a educação crítica teria condição de luta contra a massificação e a alienação, promovendo a formação de indivíduos reflexivos e emancipados, prontos para participar e promover a democracia. A educação, ao combater o processo de semiformação e a lógica da massificação imposta pela Indústria Cultural, contribuiria para o não desenvolvimento da barbárie. A educação tem o explicito papel de levar os homens a perceber as contradições da sociedade em que vivem. A educação deve ser reflexiva e emacipadora, mas esta emancipação deve ser pautada na crítica da realidade e dos condicionantes objetivos da sociedade.

A educação perdeu o seu sentido de formação a partir do momento que se tornou algo instrumental, ou seja, utilitarista e mensurável. O sujeito inserido neste processo totalizante perde sua capacidade de individuação, de agir e pensar com criticidade. Faz-se necessário que a escola recupere seu caráter de formação ampla, onde o indivíduo possa ser capaz de se tornar sujeito, ou seja, agente criador do seu próprio projeto, sem deixar-se apoderar pela Indústria Cultural. A real função social da educação é trazer o sujeito à sua humanidade, levando-o a superar os problemas e as determinações da sua realidade (ADORNO, 2011c). Isso seria educar para o esclarecimento, educar para romper com os determinismos estruturantes, educar para autonomia e para a cidadania. A construção dessa autonomia só é possível através da crítica, e a partir de relações sociais concebidas historicamente, mediante a inserção reflexiva do sujeito na sociedade. A reflexão é a chave da prática pedagógica. Não a reflexão utilitarista e mecanicista ensinada em muitas escolas, mas sim uma reflexão 
através da experiência, da individuação, do processo que é construído na alteridade, no contato e na percepção do outro. A prática educativa e pedagógica deve então criar artifícios para que o indivíduo produza seus espaços e experiências, ao passo que vai se tornando sujeito autônomo.

A escola mediante uma analise alicerçada na Teoria Crítica, deve ser o lócus da produção da autonomia, a partir de uma inflexão hermenêutica do sujeito no mundo. A partir dessa premissa a escola se torna, ou tornaria o local onde o indivíduo no processo em que se percebe enquanto sujeito, seja capaz de diagnosticar as bases da inércia e caminhar para a transformação. Para que isso ocorra em sua efetividade, a experiência da sala de aula não pode contribuir para que se ratifique a expropriação do pensamento. A educação não deve contemplar em suas práticas e nuances apenas o considerado socialmente útil ou validado, mas, principalmente aspectos que valorizem a formação plena do sujeito. E o que seria a formação plena do sujeito? Para Kant (1996) o sujeito dotado de plenitude é aquele educado para o bem, não só no que concerne a sua individualidade, mas também no que tange a participação ética na vida pública. O filosofo alemão afirma que a humanidade só pode ser desenvolvida a partir da educação e da prática pedagógica.

O homem não pode se tronar um verdadeiro homem senão pela educação. Ele é aquilo que a educação dele faz. Note-se que ele só pode receber educação de outros homens, os quais receberam igualmente de outros. (KANT, 1996, p. 444).

Quando se fala da recuperação do sentido pleno da educação, fala-se também do resgate de uma prática educativa fundada numa teoria social e filosófica pautada na realidade. Qualquer pratica ou teoria educacional será infundada se não postulada a partir das condições materiais da realidade social. A prática pedagógica calcada nesses princípios proporciona a real inserção ética dos indivíduos na sociedade democrática, se afastando portando da barbárie. Mediante a Teoria Critica esse processo de inserção e participação democrática só poderia ser forjado a partir da negação do instituído. Essa negação embora para muitos seja carregada de um viés pessimista e fatalista da análise social, é para a Teoria Crítica na verdade ir além do aparente, daquilo que é falseado pela Indústria Cultural. Neste sentido reside a importância da critica para a educação. Ademais, a escola seria o lugar do fomento de uma cultura da humanização, da construção de uma ordem social para além da massificação. 
A escola não pode ser o lócus da exclusão da expropriação, mas sim da participação, da emancipação, da cidadania. A expropriação conhecimento cerceia a humanização do indivíduo. A humanidade plena é construída e forjada no processo histórico, nas praticas e relações sociais. É a partir da negação do instituído que os indivíduos se tornam sujeitos e se qualificam para a vida em uma sociedade democrática. Uma educação danificada representa uma sociedade danificada. A premissa embora soe pessimista, é necessária para que a mudança possa se realizar. Superar a semiformação do indivíduo de fato é contribuir para sua autonomia. " $E$ preciso reconstruir a individualidade do sujeito na experiência com outros sujeitos, para que essa individualidade seja a força impulsionadora da resistência num mundo danificado. ” (ZUIN; PUCCI; OLIVEIRA, 2001, p. 131).

A ocupação com a filosofia deveria promover a identidade de seu interesse verdadeiro com o estudo profissional que elegeram, mas na verdade apenas alimenta a auto-alienação. Esta possivelmente se avoluma ainda mais na medida em que a filosofia é percebida como um peso morto que dificulta a aquisição de conhecimentos uteis, seja na preparação das disciplinas principais, prejudicando o progresso nessa área, seja na aquisição do conhecimentos profissionais. (ADORNO, 2011d, p. 69).

A reflexão é a chave para a autonomia crítica. Ao se renegar a especulação filosófica a uma espécie de limbo epistemológico, se perde o caráter crítico da educação. A reflexão está no amago tanto da abstração como da técnica em sua práxis. Para Adorno a preocupação basilar da sociologia não deveria ser essa ou aquela sociedade, e nem a sociedade com um todo. A real preocupação da sociologia enquanto ciência da investigação empírica é homem, em seus nuances e conformações particulares (ADORNO; HORKHEIMER, 1973). Uma sociedade que renega a reflexão em prol do tecnicismo exacerbado renega a própria energia criticoreflexiva existente nas atividades humanas, sejam tecnológicas ou filosóficas, pois ambas se relacionam intrinsicamente. Configura-se como um sofisma a crença na existência de uma ciência eminentemente técnica, de uma atividade profissional puramente tecnológica, que nas suas bases não esteja a reflexão filosófica.

Educa-se para o esclarecimento. Retoma-se no âmago do conceito de esclarecimento o projeto iluminista de formação do sujeito preparado para liberdade, emancipado na sua formação intelectual, política e social o que de fato humaniza. Ninguém nasce humano, se constrói como humano mediante o contato e o convívio 
com os outros homens. Apenas a experiência formativa e reflexiva é capaz de dotar o espírito de humanidade. Adorno busca a retomada do projeto iluminista da importância de se perpassar a cultura de massa, a dominação vertical e a ideologização da sociedade. Busca-se a ruptura com a semiformação, com a barbárie, com a capacidade do homem não se realizar em sua plenitude, em sua humanidade. "A auto-reflexão, o esforço crítico são dotados por isso de uma possibilidade real, a qual seria precisamente o contrário daquela dedicação férrea que a maioria decidiu." (ADORNO, 2011d, p. 69). Para Adorno os arcabouços necessários para o rompimento da Indústria Cultural, estão presentes na própria sociedade dominada pela massificação do capital. Esclarecer significa romper com a barbárie, romper com a semiformação do sujeito, ou seja, quando o sujeito percebe-se o empoderamento $^{7}$ do conhecimento. A própria sociedade do capitalismo administrado de progresso técnico, e acesso às commodities $^{8}$ dessa mesma técnica permitem a superação do status quo, do conformismo da integração, que na verdade empobrece a experiência do sujeito. $\mathrm{O}$ mundo da Indústria Cultural toma dos sujeitos a tarefa e capacidade de operar o esquematismo, ou seja, aquilo que Kant pensava como construção da razão, da interpretação hermenêutica do mundo, pois o mundo já é dado interpretado.

A função que o esquematismo kantiano ainda atribuía ao sujeito, a saber, referir de antemão a multiplicidade sensível aos conceitos fundamentais, é tomada ao sujeito pela indústria. $\mathrm{O}$ esquematismo é o primeiro serviço prestado por ela ao cliente. $\mathrm{Na}$ alma devia atuar um mecanismo secreto destinado a preparar os dados imediatos de modo a se ajustarem ao sistema da razão pura. Mas o segredo hoje está decifrado. Muito embora o planejamento do mecanismo pelos organizadores dos dados, isto é, pela indústria cultural, seja imposto a esta pelo peso da sociedade que permanece irracional apesar de toda a sua racionalização, essa tendência fatal é transformada em sua passagem pelas agências do capital do modo a aparecer como sábio desígnio dessas agências. (ADORNO; HORKHEIMER, 2006, p.103).

A emancipação não reside na integração indiscriminada, mas sim na Bildung, na formação para a liberdade para autonomia. O papel da educação incide diretamente na Bildung, na formação integral do sujeito. Não uma educação normativa, e padronizada, mas sim da resistência, e essa resistência nasce no homem na composição das suas experiências sociais.

Conferir poder ao indivíduo, em termos da capacidade crítico reflexiva de tomar decisões éticas e esclarecidas tanto em termos subjetivos, como em termos coletivos.

${ }^{8}$ Bens e serviços materiais mercantilizados 


\section{Conclusão}

Para Adorno a educação, ao combater o processo de semiformação e a lógica da massificação imposta pela Indústria Cultural, contribuiria para o não desenvolvimento da barbárie. A barbárie reforça a semiformação, e a coisificação da consciência, uma vez que destitui a reflexão de seu caráter esclarecedor, da possibilidade o sujeito por meio da crítica agir de maneira humanista, não de um humanismo retórico, mas sim um humanismo da emancipação, da autonomia do entendimento da alteridade. O sujeito semiformado, não é aquele que desconhece a técnica, a produção material, a semiformação não se vincula a ignorância total e avassaladora. A questão fundante do processo semiformatório concerne à primazia da técnica sobre a formação emancipatória. O processo de semiformação coisifica a consciência, numa racionalidade instrumental ${ }^{9}$ exacerbada, na qual a técnica e o domínio do mudo produtivo se traduzem como elementos prioritários da educação. "Os homens inclinam-se a considerar a técnica como sendo algo em si mesma, um fim em sim mesmo, uma força própria, esquecendo que ela é uma extensão do braço dos homens." (ADORNO, 2011b, p.132). A coisificação da consciência incide na massificação irrestrita do sujeito, a consciência instancia primordial da crítica, é cooptada pela Indústria Cultural, a reflexão é mero espectro, que de fato traduz um sistema de imposições verticalizadas.

\section{REFERÊNCIAS BIBLIOGRÁFICAS}

ADORNO, Theodor. A indústria cultural. In: COHN, Gabriel. Comunicação e Indústria Cultural. São Paulo: USP/Companhia Editora Nacional, 1972.

ADORNO, Theodor. A filosofia e os professores. In: ADORNO, Theodor. Educação para a emancipação. Petrópolis: Vozes, 2011a.

ADORNO, Theodor. Educação após Auschwitz . In: ADORNO,Theodor. Educação para a emancipação. Petrópolis: Vozes, 2011 b.

ADORNO, Theodor. Educação e emancipação. In: ADORNO, Theodor. Educação para a emancipação. Petrópolis: Vozes, 2011c.

ADORNO, Theodor. Educação: para que? In: ADORNO, Theodor. Educação para a emancipação. Petrópolis: Vozes, 2011d.

ADORNO, Theodor; HORKHEIMER, Max. Dialética do esclarecimento. Rio de Janeiro: Jorge Zahar Ed, 2006. 
ADORNO, Theodor; HORKHEIMER, Max. O conceito de Sociologia. In: ADORNO, Theodor, HORKHEIMER Max (Orgs). Temas Básicos de sociologia. São Paulo: Cultrix/USP, 1973

ADORNO, Theodor. O que significa elaborar o passado. In: ADORNO, Theodor. Educação para a emancipação. Petrópolis: Vozes, 2011d.

ADORNO, Theodor. Prismas: crítica cultural e sociedade. São Paulo: Editora Ática, 1998.

COHN, Gabriel. A sociologia como ciência impura. (Apresentação à edição brasileira). In. ADORNO. Introdução à sociologia. São Paulo: Editora Unesp, 2009.

KANT, Immanuel. Sobre a Pedagogia. São Paulo: Editora UNIMEP, 1996.

MAAR, Wolfgang. Adorno, semiformação e educação. In: Educação e Sociedade. Campinas, v. 24. n. 83, ago.2003.

PLFUGMACHER, Torsten. Reconstrução empírica da aula: a relação dialética presente no processo pedagógico. In: Teoria Crítica e crises: reflexões sobre cultura, estética e educação. PUCCI, Bruno; COSTA. Berlamino C. G; DURÃO, Fábio A. (Orgs). São Paulo:, Autores Associados, 2012.

ZUIN, Antônio; PUCCI, Bruno, OLIVEIRA, Newton. Adorno: o poder educativo do pensamento crítico. 3 ed. Petrópolis. Editora Vozes, 2001. 